\title{
Design of Data Model for Urban Transport GIS
}

\author{
Wen Zeng ${ }^{1,2}$, Xiaojie Chang ${ }^{2}$, Jianjun Lv ${ }^{1,2}$ \\ ${ }^{1}$ Faculty of Information Engineering, China University of Geosciences, Wuhan, China \\ ${ }^{2}$ Zondy Cyber T\&S Co., Ltd, Wuhan, China \\ E-mail: Zengwen69@163.com
}

\begin{abstract}
Constructing the data model for public transportation by integrating the spatial and the non-spatial information, is the basis of reasonable plan and effective management of urban public transport. This paper presents a transit data model based on geographic information systems (GIS) technology, which utilizes arc-node networks, and manages the foundational bus data with point, link, polygon and record features. In this model, a transport network is generated and maintained in a dynamic manner, and hence supports planning, construction, management, operation and optimization functions for transit facilities and routes, as well as day-to-day transactions. Public transportation GIS established on this model foundation will remarkably upgrade the construction level and the urban service ability.
\end{abstract}

Keywords: Geographic Information System (GIS), Transit GIS, Transit Route Network, Data Mode

\section{Introduction}

With the rapid urban development, the population and vehicles increase faster and faster which bring more and more pressure for urban traffic. Improving public transportation is the key to solve this problem. To improve service quality and efficiency of bus, subway and other public transportation, it's urgent to promote pubic transportation informationization. From the national application trend, GIS has been the most effective method to foster public transportation informationization development. [1,2].

Transportation GIS which integrates spatial and nonspatial information, integrates computer network, spatial database technologies which supports map surveying, data surveying, real-time acquisition, spatial analysis and expert knowledge base. It can manage and assess the urban roads, public transportation network, the station facilities, basic data and the bus operator information which realizes various business functions.

Urban public transport system based on GIS will display the overall distribution of urban public transportation which achieves basic GIS functions, such as, add, modify, delete, query and browse related attribute of basic topographic graphics, road, station grounds, bus

Fund Project: Research and demonstration of key technology of urban municipal infrastructure management and operation, Key projects of science and technology subjects, National Eleventh Five-Year Plan, (No.2006BAJ15B03). lines and operation data. What's more, it can conduct analyze and assess public transport facilities and routes reasonable layout based on the evaluation system and the knowledge base. GIS data model organizes data in different basic operation unit (such as point, line, surface, net, etc.), according to spatial entities and non-spatial information characteristics and describes entities relations by defining topology, relationships and constraints $[3,4]$. Public transport information is various which needs to be appropriate organized. Data model design is the basis for Public transportation research and development.

This paper presents public transport data model which can establish and create routes in real time, separate road layer and route layer, and separately manage route layer. The generation of route is based on site data and site routes. Public transport route generation has the several steps, such as, generating route site by site mapping the centerline and seeking the shortest path by centerline adjacent sites. It will improve the route accuracy and facilitate route analysis.

\section{Management Object Analysis}

Urban public transport managed objects, includes physical entities and data entities. Physical entities refer to the road network, public transport facilities, routes, vehicles, passenger traffic distribution and other objective object. 
Data entities are mainly public transport daily operation and management data, such as travel schedule, IC card credit card data, traffic statistics, sales data, and personnel management data.

Road network is the basis for all traffic information system and road network modeling is widely discussed. The actual model includes the arc-node data model (plane or non-flat), along the driving direction model, along driveway model, etc. Data entities are generally in the form of database table and every table are correlated by keyword. This paper mainly studies the public transportation facilities, lines, modeling, and operation data such as, operations and evaluation data.

\subsection{Public Transport Facilities}

1) Platform: Bus station is set on both sides in pairs. According to actual passenger traffic and geological location, it can be divided into three types, hub, the starting and ending, and common site. The hub is usually in a downtown with heavy traffic and large population which has great impact on urban management and operation.

2) Station: Mainly refers to parking lot and maintenance place. Parking lot is used to park buses which need to manage and dispatch buses according to the number of vehicles and starting-ending time.

\subsection{Routes}

Urban public transport bus route is the most important part of urban transportation which refers to the directed physical path $[5,6]$ of every bus route. Bus lines are divided into one-way line and ring lines. One-way line contains uplink and downlink lines. The round-trip journey can be regarded as different paths. According to fixed order and the passed sites, determine the spatial location and morphology of bus route [5,6].

In data model, one line is alternatively connected by site and road section.

1) Site: Site is location for passengers getting on and off the bus. Actually, site is the "projection" of platform on one specific line and its location is according to the corresponding site. In fact, different buses lines may overlap and multi-lines may pass the same site. In other words, the platform and site has one-to-many relation.

2) Road sections: Section is a line segment between adjacent sites which is the basic building blocks unit of bus routes. Specifically, section is the connection of two adjacent sites along the road centerline.

The following diagram visually reflects the relationship between buses related objects:

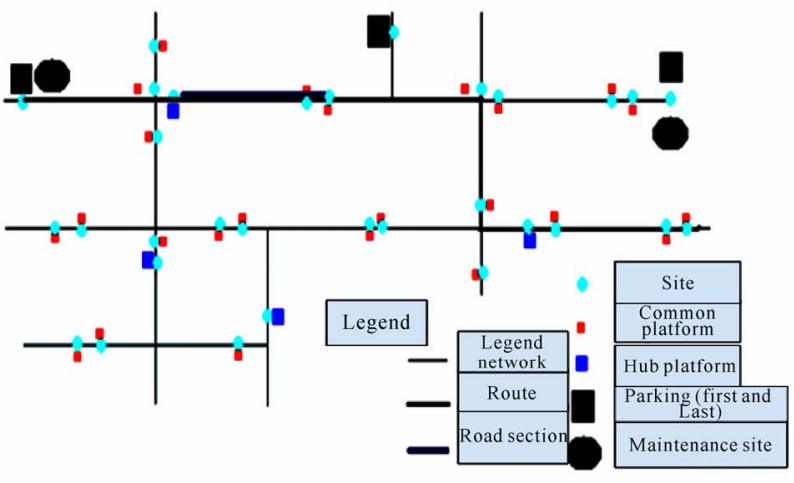

Figure 1. Objects relations of public transportation.

\subsection{Operation Information}

Public transport operation information is bus GIS information which is closely connected with the application business data including the frequency plan, passenger traffic and passenger revenue and other data. It organizes public transportation information.

The actual performance of public transport operations is reflected in many aspects, such as vehicle storage and organization, each line transceiver classes, schedules, operating interval, operation mileage management, lines traffic, operation income, etc. Related information and route will change accordingly.

\subsection{Evaluation Index}

Urban bus routes operation should be standardized by general regulations and supports. The macro index of public transportation is main involved in seven factors, the whole length of operation network, vehicle admission rates, bus travel proportion, bus site coverage rate, transfer coefficient, line density and line repeat coefficient. These factors change with time periods which reflect the overall condition of urban public transportation distribution density, service area, public travel convenience, etc.

\section{Data Model Design}

\subsection{Overall Model}

Public transport Information lies in urban infrastructure and urban road network data. You can see the organization correlations public transportation models in Figure 2.

In the model, the site data are abstracted from the actual platform which is taken as node in lines. Each site has one unique platform which recorded by its spatial geological location and expressed by point feature. Hub 


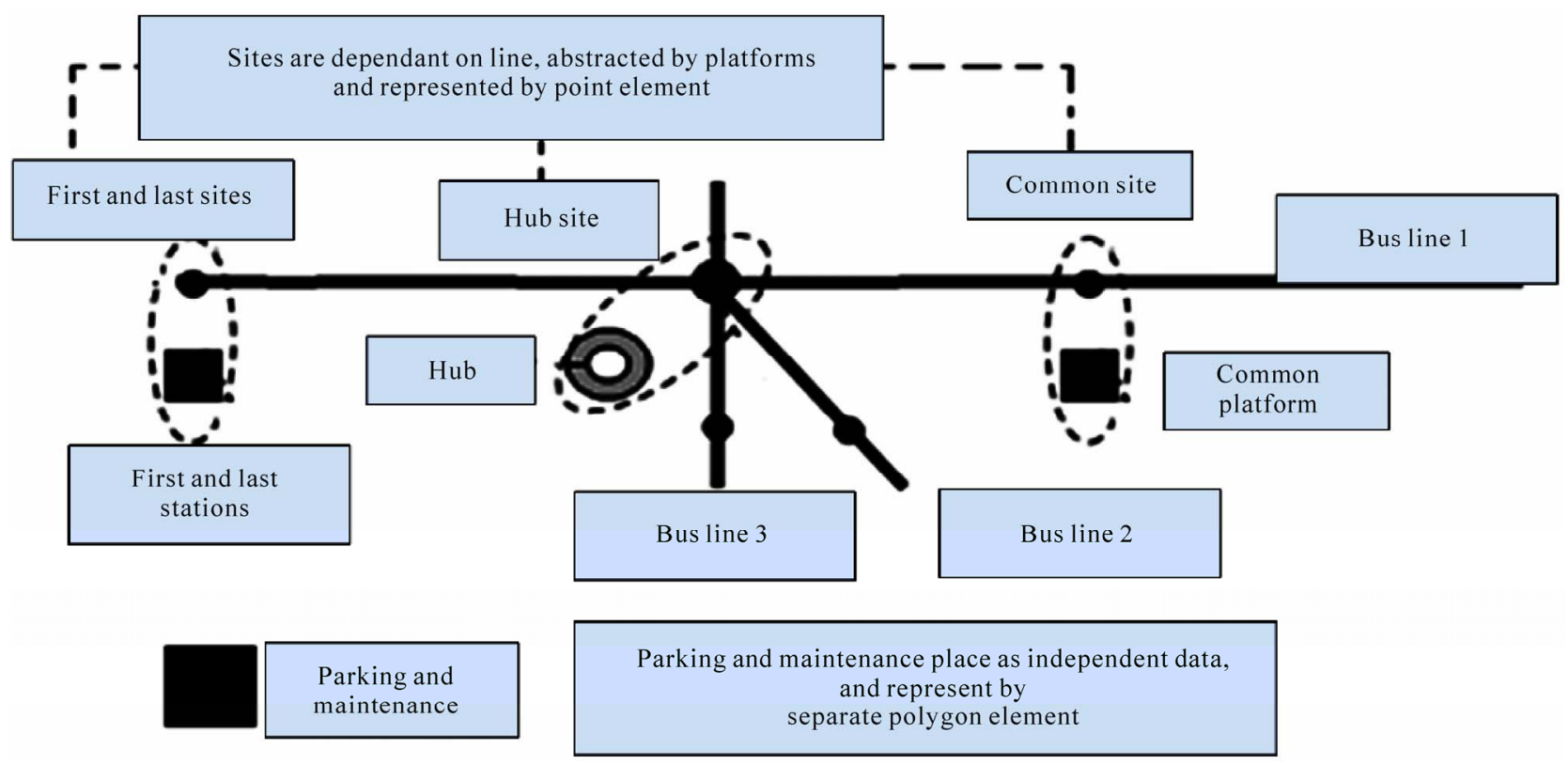

Figure 2. Data model of urban transportation.

site corresponding station is the platform data which has relatively complex attribute information. It's usually expressed in polygon element. All the sites corresponding to the platform passed by bus is closely related to site location. Parking and maintenance field is relatively independent which can be individually expressed.

\subsection{Data Representation of Public Transportation Management Object}

Data contents in public transportation management consists four parts, public transportation station, lines, line network and subsidiary business data. Station and line data in bus actual application has two major categories, the current data and planning data.

\subsubsection{Public Transportation Station Data}

Bus station data contains site and station two parts. The subsidiary attributes information of station and bus hub site are relatively complex which record the number of vehicles and their location and covered area. It will help vehicles management and bus operation analysis and represented in polygon features. The first, last station and the halfway stops are relatively simple which is the connection of every routes. It only relates to the passed lines and represented in points feature. It helps recording the spatial location of entities.

\subsubsection{Public Transportation Route Data}

Every bus route data not only record all the passed sites and relations, it also records large number of public transportation professional data. It will directly affect the operation analysis and comprehensive evaluation of pub- lic transportation system. Therefore, this model uses database table to store data. Actually, public transportation has uplink and downlink lines. The passed sites are not completely the same, and some lines are even single line (loop). This model takes every line as one closed loop, and records every passed site number of the uplink and downlink lines.

\subsubsection{Public Transportation Line Network Data}

Public transportation network does not exist in practice. It's only the correlation record of point entity coordinates of current site data and current site and lines. Then generate route network information, which record the topological relations of site and routes. Therefore, it's stored in network element structure.

Single-line network generation diagram is as follows. The virtual circuit displays the passed platforms of lines vividly. The uplink and downlink line form a closed circuit, which doesn't exist in practice. Actually, the bus routes are overlapped by the road centerline. Therefore, in order to clearly display the uplink and downlink lines, migration processing has been done. In the process of line generation, the platform is mapped to the centerline sequentially. Then seeks the shortest path of the adjacent sites, such as add control point at the corner (Shown in Figure midpoint bc1 and bc2), connect the generated site, thus finally get the route.

\subsubsection{Public Transportation Subsidiary Data}

Subsidiary data main contains operation information and macro information. Operational data includes public transportation IC credit card data, distribution data of bus traffic, distribution data of bus traffic, and the existing 
public transportation network data. Macro data, includes bus number, the proportion of bus travel, public transportation network density, public transportation nonlinear coefficient, bus lines coverage, transfer coefficient, etc. A large number of attribute information can be stored in operation information and macro information database table.

\subsection{Correlation}

As for public bus transportation data, site and route are closely related, which is also the base for bus network. Other data are relatively independent. This data model proposes the following correlations to ensure the rationality and integrity of line network data.

1) Route and site, in one route there are many sites, the current bus lines and current site form one-to- many relations.

2) Routs and line network, site route table records all the site information of every passed bus, and thus generate a bus route which is the base for the urban bus network. The bus route and line network form many-to-one relationship.

3) Route and single-line, urban bus routes constitute bus line network. Each bus route is corresponds to one line in the network.

4) Site and platform, there are many lines in each platform which corresponds to site of each line. Platform and site has form one-to-many relationship.

5) Operation information and routes: Operation information bases on specific routes. The operation line mileage, passenger traffic, passenger data and traffic income are different for the same destination in different time periods.

\subsection{Line Network Generation Process}

From Figure 3 we can see the single line network generation process. Figure 4 flow chart describes the specific concepts and algorithms of line network generation. (The following are the description of the chart)

\section{Data Model Realization}

\subsection{Database Organization}

Based on data model design, bus related basic data, site field data of parking, maintenance field and hub station information, planning site and line data, and independent macro information need to record the information separately. Operation information is separately stored while it connected with lines. Current site and line data are correlated. All the above data form a transportation network.

1) Current site data: Record site number, name, location, type, and their respective sections and site. It also records the area, parking area and construction area.

2) Current line data: It records route designation, dock site in turn, first and last bus time and bus intervals. It also records various attribute information, such as, line length, total number of line vehicles, ticketing form and full line rate, average transport distance and non-linear coefficient.

3) Current site lines information: It records the correlation of each line and its corresponding site. One line record relates to multi site record. In addition, it contains the route length and non-linear coefficient. This table records and stores the correlation of sites and routes.

4) Public transportation network: It records designation of each route and all sites number and geometric information on this route. The network file is formed by the relations of site and route of site data and site line table. It records the geospatial location and topological relations of all the bus routes.

5) Station data: Data of parking and maintenance field and repair shop is relatively independent. It records spatial and attribute in polygon file.

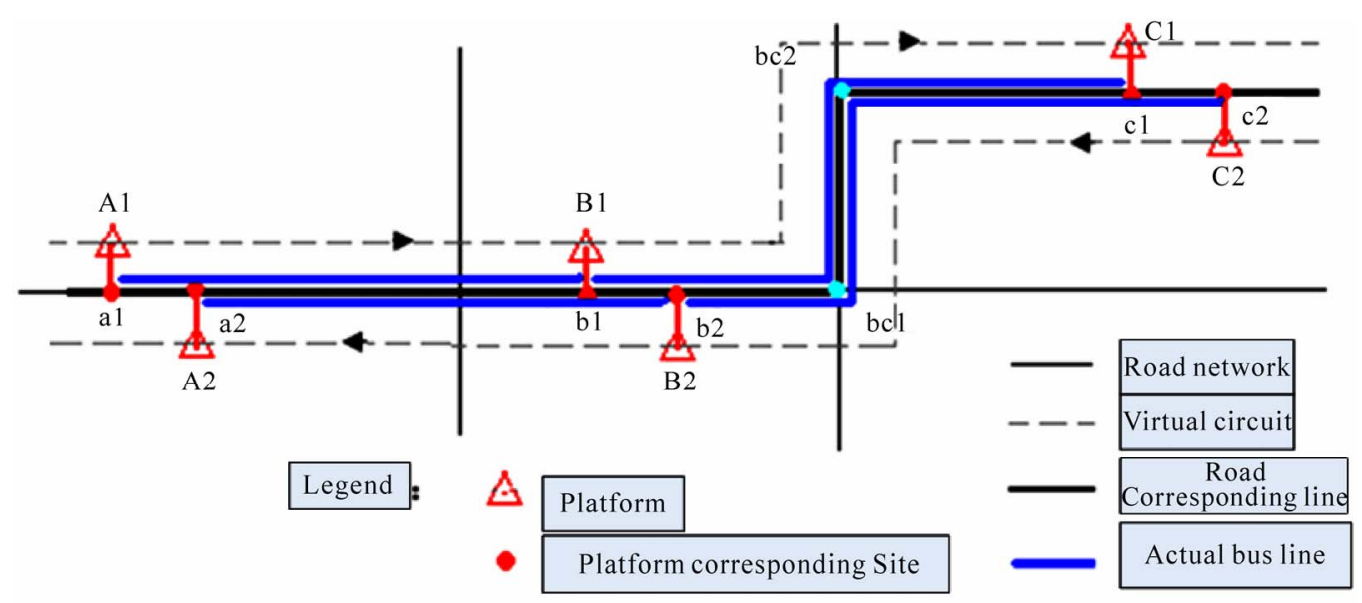

Figure 3. Single-line network generation diagram. 


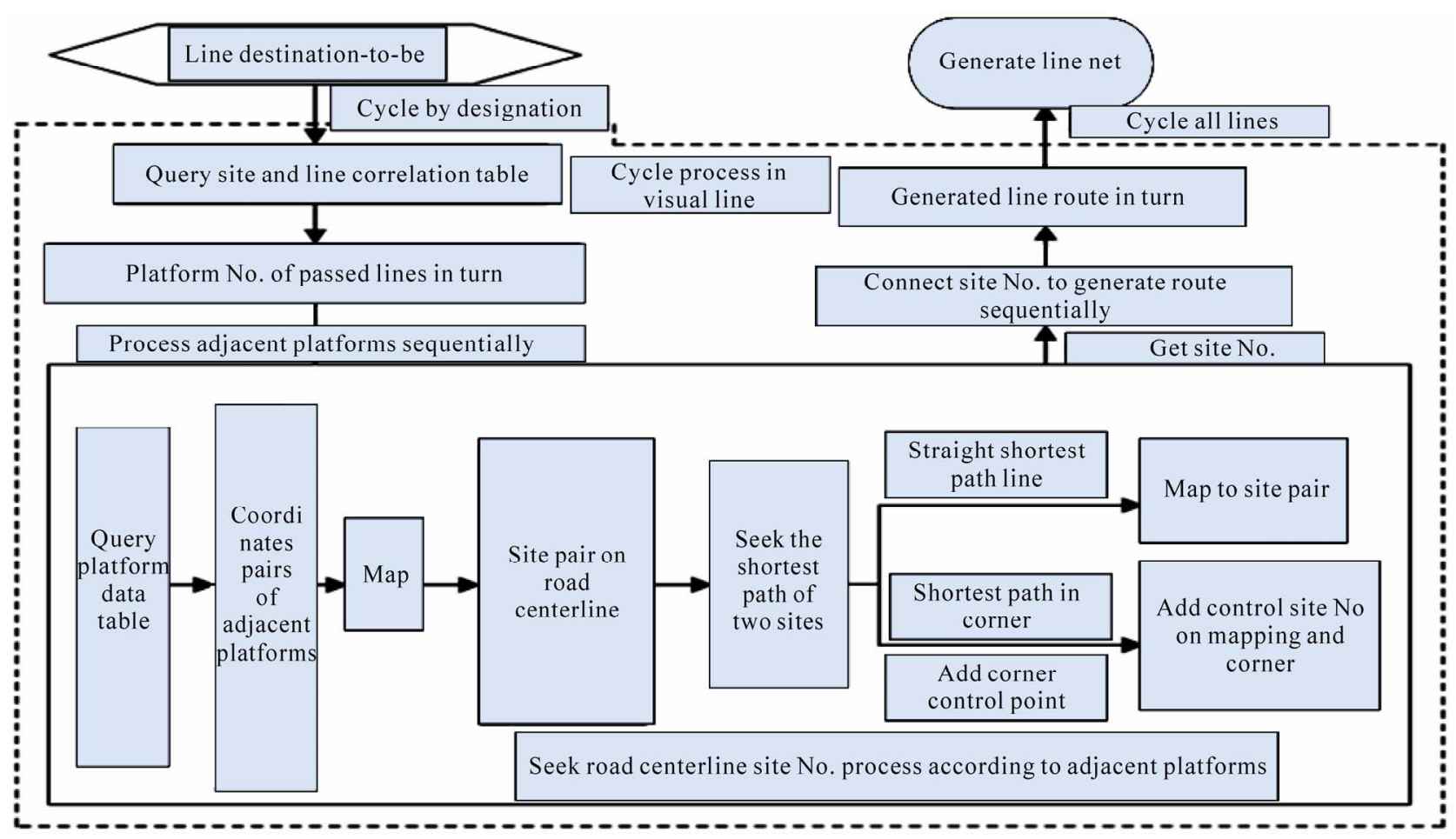

Figure 4. Flow chart of arithmetic.

6) Subsidiary data: Bus operational information and macro information store the bus operation related attributes. Operational information associates with the route and time. The file records the lien destination and date.

\subsection{Correlation Realization}

In accordance with the database organization, some of bus data are independent and some are interrelated. You can see vividly about the correlation of data from Figure 5. In Figure 5, current bus sites and current lines are correlated through site number and ID. The current site file and bus line file are connected by site number field. Current bus line file and current site file are connected by line designation field. Bus line net file and site line file are correlated through destination field. Bus operation

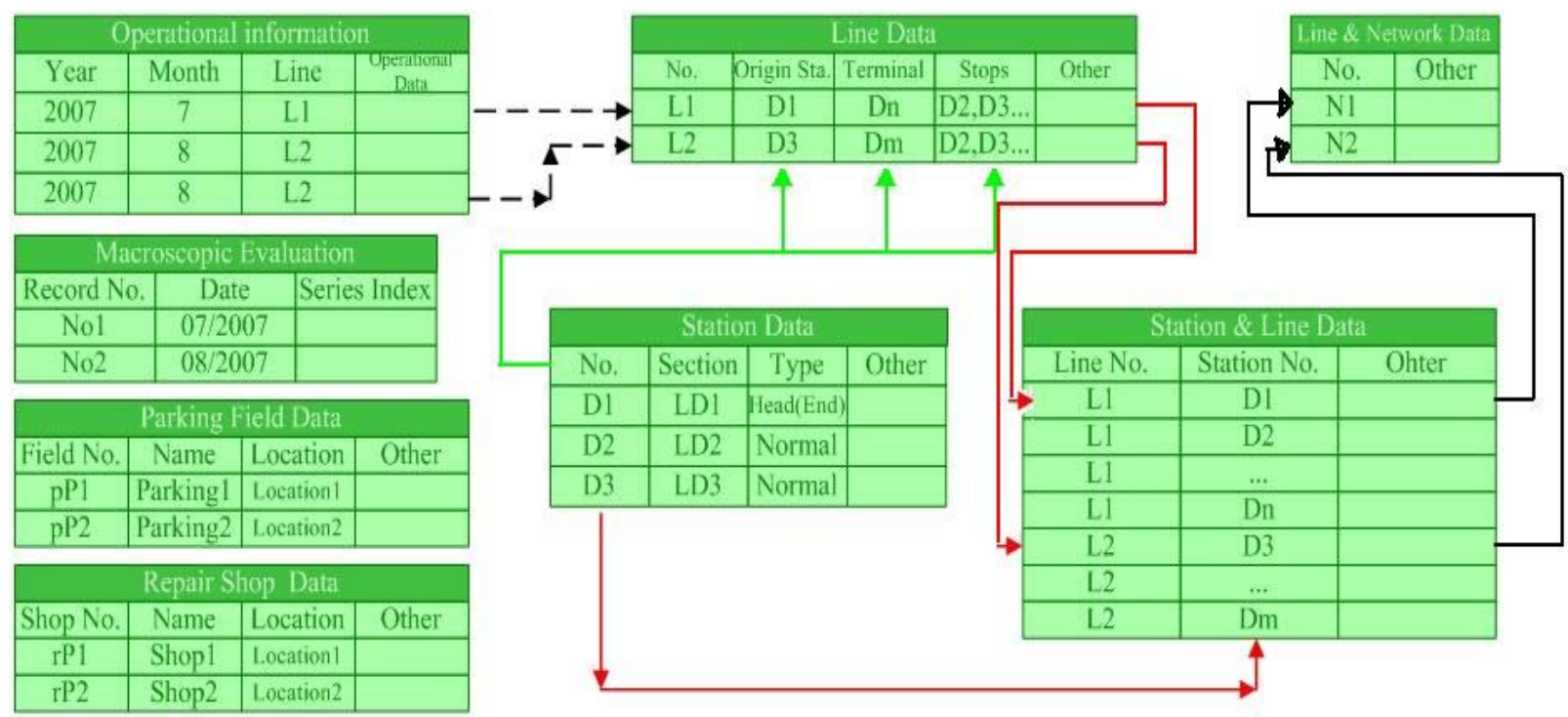

Figure 5. Correlations among the data tables in data model. 
information and lines are connected by line destination. The macro-evaluation data are independent from site field data.

\subsection{Database Realization}

\subsubsection{Data Entry}

Bus station site data and route data are the basis of bus model and the system. The station site, line and data of every site will be input in database provided by user. Passenger traffic distribution data and site information can be input in table file in establishing lib, or by system. The historical data of operational information and macroevaluation information can be directly manually input to the database and the new records can be added through the system functions.

\subsubsection{Real Time Generation}

Bus lines are the most important data and the lines aregenerated on the site route record. Site route file sequentially records corresponding relationship of one line and the sites that it passed which is generated by the line sequentially passed site information record. One line relates to multi-records. According to the line record, the bus transport number and passed site number, and search relative site spatial information according to site number in site files, record site location, and connect all the records sequentially to generate a route. At the same time, every single line is saved in bus line net file and all the single line constitutes the whole bus network.

The following diagram shows the final outcome of generation one single line net. The site name is marked on the line in turn, and the uplink and downlink line is marked in different color.

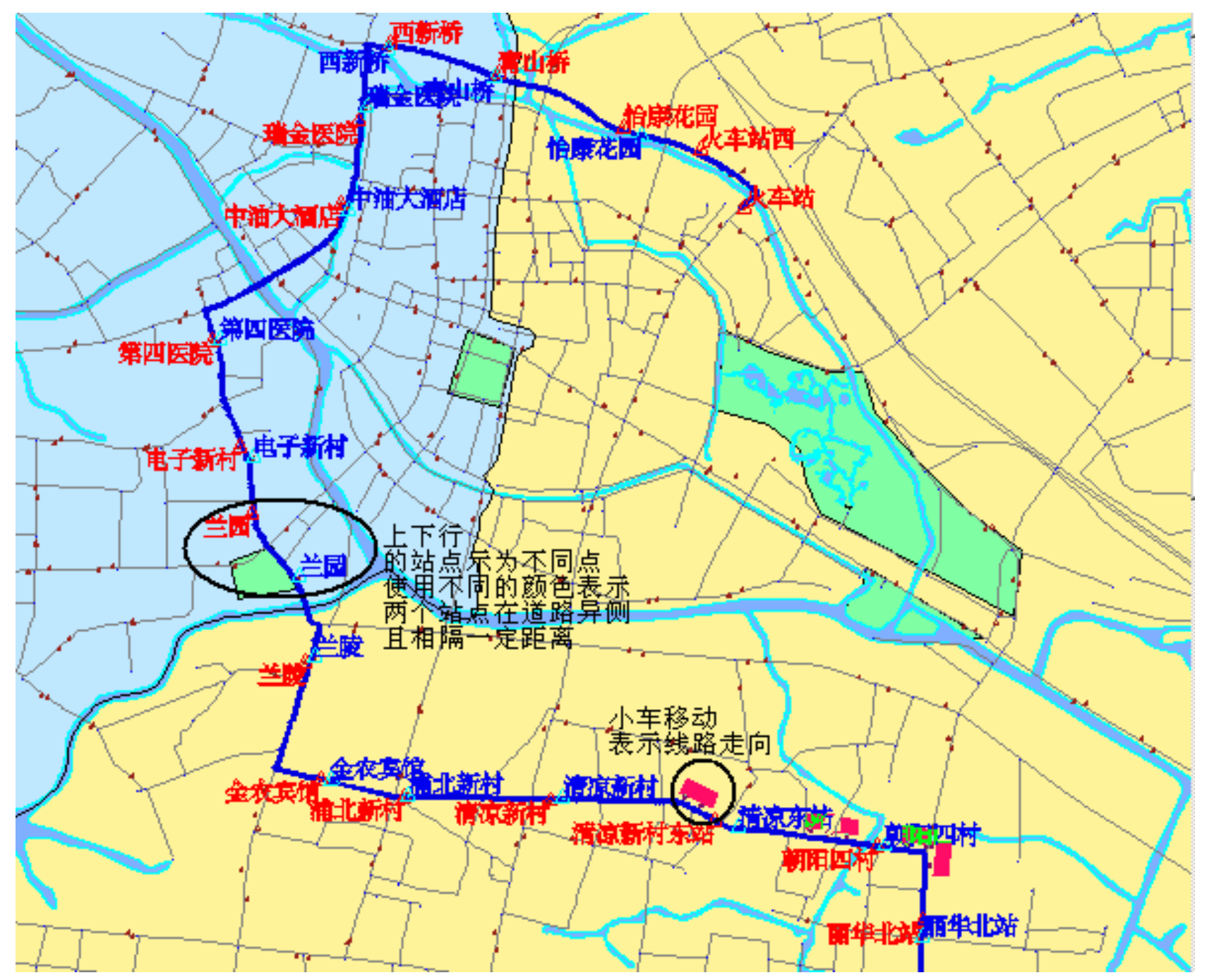

Figure 6. Result generation of single linear network. 


\section{Conclusions}

Urban public transport is the public welfare undertakings for urban economic development and people's life. It also represents the degree of municipal construction modernization. This paper introduced a new transportation data model which can establish and maintain route network in real time. The main features are embodied as follows, separation of road layer and route layer separation, and route display doesn't rely on road net, route site generated by the mapping of station site to centerline, the geological location of route are more accurate, line generation algorithm is independent of any line, only related to site location and road conditions, so user can add, delete, and modify the route. In addition to basic GIS data processing function, the system store and manage public transport site data, operation and macro-information which can effectively organize urban public transportation planning and information management. The system has good expansibility, which will better serve urban public transportation GIS and foster urban development.

\section{References}

[1] W. Z. Xiao, W. Wang, X. G. Li, et al., "Application of Urban Public Transportation Planning Information System Based on GIS,” China Geographic Information System Association Essays, 1999, pp. 1001-1005.
[2] T. Huang, "Study on Design and Application of Urban Communication Geographic Information System," Sanjin Surveying, Vol. 9, No. 3-4, 2002, pp. 63-66, 78.

[3] J. Chen and S. W. Zhang, "The Third Generation GIS Data Model and Its Realization,” Sanjin Surveying, Vol. 10, No. 2, 2003, pp. 7-9.

[4] W. Zen, "GIS Software Project," China University of Geosciences Press, Wuhan, 2002, pp. 34-40.

[5] J. T. Li and J. F. Yang, "Public Transport Network Model and Route Query Application Based on GIS,” Journal of Dalian Railway Institute, Vol. 25, No. 2, 2004, pp. 30-33, 95.

[6] H. Wen, Y. F. Liu and J. H. Zheng, "Public Transport Network Data Model Research Based on Time Chain," Geology and Geological Information Science, Vol. 21, No. 3, 2005, pp. 35-38.

[7] Y. Li and Z. D. Huang, "Multi-Layer Public Transportation Site Model Based on UML," Communication and Computer, Vol. 24, No. 133, 2006, pp. 13-17.

[8] Z. Hu, F. Y. Zhang and S. L. Liu, "Research and Algorithm Realization on Urban Bus Transfer Data Model," Telecom Network Technology, Vol. 4, 2007, pp. 71-74.

[9] X. C. Wu, "Geological Information System Design and Realization,” Electronics Industry Press, Beijing, 2002, pp. 91-112.

[10] E. Geneidy and A. Medhat, "The Use of Advanced Information Technology in Urban Public Transportation Systems: An Evaluation of Bus Stop Consolidation,” Dissertation Abstracts International, Vol. 66, No. 3, p. 1190. 